\title{
A Dialectical View on Conduction: Reasons, Warrants, and Normal Suasory Inclinations
}

\author{
SHIYANG YU
}

Department of Philosophy, Institute of Logic and Cognition

Sun Yat-sen University

135 Xingang Road West, Guangzhou, P.R. China

\section{FRANK ZENKER}

Philosophy \& Cognitive Science

Lund University, 22100 Lund, Sweden

frank.zenker@fil.lu.se

Abstract: Carl Wellman (1971) introduced the reasoning-type conduction while endorsing a dialectical view on natural language argumentation. Contemporary scholarship, by contrast, treats conductive argument predominantly on a product view. Not only did Wellman's reasons for a dialectical view thereby fall into disregard; a producttreatment of conduction also flouts the standard semantics of 'argument'. This paper traces why Wellman held a dialectical view regarding the role of defeasible warrants. These act as stand-ins for (parts of) value hierarchies that arguers of normal suasory inclination find acceptable. We also improve on how to diagram conduction and distinguish two of its structural variants.
Résumé: Carl Wellman (1971) a introduit la notion d'argument conducteur tout en souscrivant à une vision dialectique de l'argumentation dans le langage naturel. Les études contemporaines, en revanche, traitent un argument conducteur principalement comme un produit. Elles ont non seulement pas tenu compte des raisons avancées par Wellman pour appuyer une vision dialectique, leur interprétation qu'un argument conducteur est un produit fait également fi de la sémantique standard de «l'argumentation». Cet article explique pourquoi Wellman avait une vision dialectique du rôle des lois de passage révocables. Celles-ci agissent comme des substituts pour les (parties de) hiérarchies de valeurs que les raisonneurs, doués d'une inclination à persuader normale, trouvent acceptables. Nous améliorons également la manière de schématiser un argument conducteur et de distinguer deux de ses variantes structurelles

Keywords: claim-to-validity, conductive argument, degrees of importance, dialectical view, pro and con reasons, product view, value hierarchy

(C) Shiyang Yu. Frank Zenker. Informal Logic, Vol. 39, No. 1 (2019), pp. 32-69 


\section{Introduction}

Carl Wellman $(1971,54)$ introduced 'conduction' to denote a type of ethical reasoning. He viewed both conductive reasoning and the natural language arguments that express it as importantly distinct from deduction and induction. Though this inspired scholars to recognize a third inference type (e.g., Freeman, 1983, 10; Johnson \& Blair, 2000, 99; Walton, 2001, 167), Wellman did neither advocate the deduction $v s$. induction $v s$. conduction-distinction as exhaustive nor did he restrict the relevance of conduction to ethical contexts alone.

Wellman distinguishes three conductive patterns. With two of these patterns, arguers provide either a single or, respectively, several reasons for a conclusion (Wellman, 1971, 55f.). Our paper focuses on arguments that follow the third pattern, where "reasons against the conclusion are included as well as reasons for it," so that "some conclusion is drawn from both positive and negative considerations" (ibid., 57). It is this third pattern that scholars variously refer to as a 'conductive argument', a 'pro and con argument', or a 'balance-of-considerations argument'.

With notable exception (e.g., Johnson, 2011; van Laar, 2014; Wohlrapp, 1998; 2008), most scholars have adopted a product view on conductive argument (e.g., Blair, 2011, 2016; Fisher, 2011; Freeman, 1991; Govier, 1999; 2010; Hansen, 2010; Hitchcock, 1983; 2007; Jin, 2011; Walton, 2011; Zenker, 2010). This view treats a conductive argument as an inferential object "abstracted from the ongoing communicative interaction [or process] of rhetoric or dialectic" (Wenzel, 1992, 127f.), an object that is itself constituted by "a set of statements consisting of premises and conclusion, or claim and support" (ibid., 125; see van Eemeren et al., 2014, 438).

A product view on conductive argument, however, misaligns with the meaning of 'argument' as a reason-claim-complex whose premises an arguer offers as exclusively supporting a conclusion. We detail this issue, outline three potential solutions, but reject each as inadequate (Sect. 2). With Wellman, we treat conductive argument on 
a dialectical view instead (3), and particularly address its structure and its defeasibility (4). Our conclusions are in Sect. 5.

\section{Counter-consideration and the semantics of 'argument'}

\subsection{Overview}

This section shows why counter-considerations break with the standard meaning of 'argument' (2.2), outlines three "conservative" ways to achieve realignment (2.3), but argues that each fails (2.4). Sect. 3 then favors a dialectical view.

\subsection{Two features}

As Jin $(2011,11)$ (rightly) observes, "either in ordinary language or in logical textbooks, the term 'premise' is usually used to mean a proposition that supports or is supposed to support a conclusion." A conductive argument, by contrast, features at least one counter-consideration directed either at the argument's conclusion, at one or more of its premises, or at the premise-conclusion link. This, however, violates the following two features of argument-as-product:

1. An argument has exactly two types of components: at least one premise and exactly one conclusion. ${ }^{1}$

2. Singularly or jointly, the argument's premise(s) exclusively offer support to its conclusion.

To specify the second feature, the premises need not support the conclusion objectively. It suffices that an arguer offers them exclusively as reasons for believing that the conclusion is true or acceptable, or as reasons to act as if this were the case (See Sect. 2.3; hypothesis (6).).

\footnotetext{
1 Though some scholars distinguish a separate conclusion-indicator (e.g., "hence," "so," "therefore") or a premise-indicator (e.g., "because," "since") as a third component, we see no need to do so. Instead, we view the conclusion-indicator, respectively the premise-indicator, as a part of the conclusion, or the premise.

(C) Shiyang Yu. Frank Zenker. Informal Logic, Vol. 39, No. 1 (2019), pp. 32-69
} 
Both features standardly apply to both deductive and inductive arguments-as-products, but not to conductive arguments-as-products. For the latter include counter-considerations that offer negative support. To maintain the second property as a defining feature of 'argument', therefore, many scholars treat a counter-consideration as a third component besides premises and conclusion. As this, in turn, violates the first feature, however, one would either have to reject both properties (as defining features of 'argument'), or accept that a conductive argument is what Lakatos (1978) calls a conceptual "monster."

Our monster-barring strategy (ibid.) is to leave both features intact, for which three conservative solutions and one "radical" solution offer themselves. We may treat a counter-consideration either as part of the conclusion (solution $\mathrm{S}_{1}$ ); as an argument component besides premise and conclusion $\left(\mathrm{S}_{2}\right)$; as a premise that negatively supports the conclusion $\left(\mathrm{S}_{3}\right)$; or we refrain from treating conduction as argument-as-product in the first place $\left(\mathrm{S}_{4}\right)$. Fig. 1 outlines these options:

Focal question: Should one treat conduction as argument-as-product?

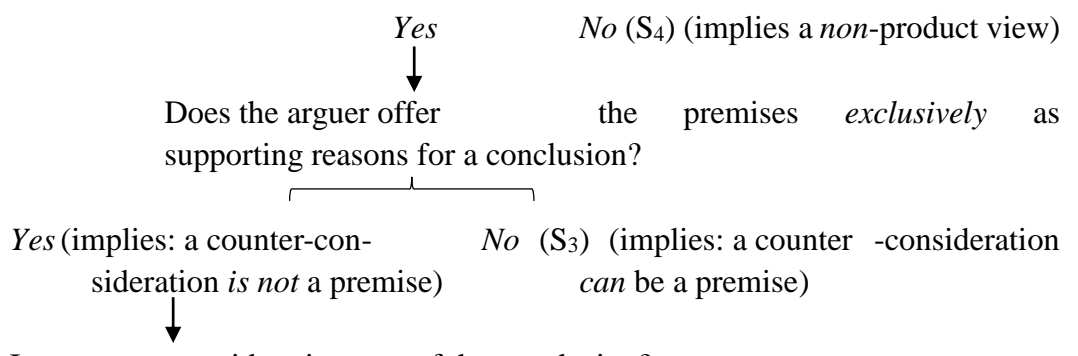

Is a counter-consideration part of the conclusion?

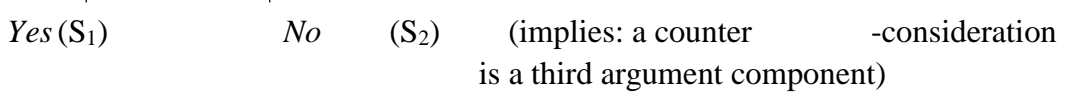

Fig. 1 Decision tree as to whether one should treat conduction on a product view 


\subsection{What counter-considerations are not}

Hansen $(2010,35-40)$ offers a slightly more complex classification than our Fig. 1. He offers six hypotheses on what a counter-consideration could be: (1) a premise (i.e., our $\mathrm{S}_{3}$ ); (2) a background knowledge-item $\left(\mathrm{S}_{2}\right)$; (3) a conclusion-qualifier $\left(\mathrm{S}_{1}\right)$; (4) an "antipremise" originating with a counter-argument $\left(\mathrm{S}_{4}\right)$; $(5)$ a consideration that, like a premise, is relevant to the conclusion $\left(\mathrm{S}_{3}\right)$; $(6)$ a consideration that - or so the arguer claims in an on-balance premisecounter-considerations outweigh $\left(\mathrm{S}_{3}\right)$.

Hansen rejects (1) to (4), accepts (5) as a viable but under-describing solution, then sides with (6). As reasons he offers the following: premises should be positively relevant to the conclusion (this rejects 1); a conductive argument not only mentions but also considers a counter-consideration (rejects 2); though a counter-consideration pertains to the conclusion, this does not make the former a part of the latter (rejects 3); a conductive argument is one argument instance, rather than two instances (rejects 4). While Hansen finds (5) acceptable, he (correctly) observes that (5) merely names a general property, one that most theorists would probably accept. Yet, (5) does not say what conduction $i$.

Having exhausted the options, Hansen sides with (6), thus treats a conductive argument as one, and only one, argument featuring premises and a conclusion, whose counter-considerations - themselves neither premises, nor conclusions, nor parts thereof-make for a third argument component (called 'counter-reason'), one that a conductive argument both mentions and considers.

In siding with (6), Hansen endorses our $\mathrm{S}_{2}$, as does Govier (1999; $2005 ; 2010)$. By contrast, Jin (2011) finds $S_{2}$ and $S_{3}$ equally viable; Wohlrapp $(1998 ; 2014)$ prefers $\mathrm{S}_{4}$; Hitchcock $(1983,50-53)$ opts for $\mathrm{S}_{3}$ (implying that a counter-consideration can be a premise). In fact, $\mathrm{S}_{3}$ seems to be Wellman's own preference. For "[a] premise is any consideration (that is, anything that can be considered or attended to) which counts or is thought to count for or against the conclusion" 
(Wellman, 1971, 90; italics added). As Sect. 3.3 will show, however, Wellman does not adopt a product-view. As per $\mathrm{S}_{4}$, he instead treats conduction on a dialectical view (aka argument-as-process), making Wohlrapp's choice exegetically correct.

Rather than reconcile counter-considerations with the two standard criteria of argument-as-product (see Sect. 2.2), we too treat conduction on a dialectical view. Unlike Wellman or Wohlrapp, however, we seek to align with the standard meaning of 'premise' as an element an arguer exclusively offers as positive support.

Now turning to Wellman's best-known example of a conductive argument, we first argue against $S_{1}$ to $S_{3}$. Sect. 3 then offers positive reasons for $\mathrm{S}_{4}$.

\subsection{Why $S_{1}$ to $S_{3}$ do not convince}

Wellman's probably most frequently cited example features two reasons, each of which by itself provides insufficient support to the conclusion.

Although your lawn needs cutting, you ought to take your son to the movies because the picture is ideal for children and will be gone by tomorrow. (Wellman, 1971, 57)

One of the two reasons supports viewing the movie simpliciter because it is ideal for children; the other supports viewing the movie today, for it will be gone by tomorrow. Properly understood, then, the overt conclusion 'you ought to take your son to the movies' leaves 'today' implicit. Moreover, neither reason by itself sufficiently supports the argument's explicit conclusion. Rather, both premises are mutually independent and generate their argumentative support jointly. Therefore, the argument is convergent, or what 
pragma-dialecticians call coordinative (van Eemeren \& Grootendorst, 1992, 76-82; Snoek-Henkemans, 2001, 101). ${ }^{2}$

Scholars who opt for $\mathrm{S}_{1}$ interpret the focal counter-consideration-'your lawn needs cutting' - as a part of the conclusion, C. They would consequently read the explicit conclusion as: 'although your lawn needs cutting, you ought to take your son to the movies today'. The two premises, hence, are: "the picture is ideal for children" and "the picture will be gone by tomorrow". Were both premises to occur in an actual context, however, then one might readily arrive not at this reading of $\mathrm{C}$, but rather at the comparatively simpler reading: "you ought to take your son to the movies today." This would render $\mathrm{S}_{1}$ implausible.

Although the exact reading that ordinary arguers do arrive at more readily is an empirical matter, $\mathrm{S}_{1}$ nevertheless remains a possible analysis. After all, assume that the son's parent entertains a pro-attitude towards "you ought to take your son to the movies." Further, grant that an arguer would probably anger the parent by trying to persuade her otherwise in a direct or confrontational manner. The most viable persuasion attempt without angering the parent, then, is this: affirm her pro-attitude while raising a contrary reason as part of the conclusion, thereby reminding of the counter-consideration rather than confronting her with it.

As this allows an arguer to endorse the positive supporting reasons (good "kid-flic"; soon gone) while using the focal counter-consideration to persuade otherwise, it may seem to vindicate $S_{1}$. Yet, neither "you ought to take your son to the movies," nor "although your lawn needs cutting, you ought to take your son to the movies" is the arguer's own conclusion. The arguer rather looks for the most

\footnotetext{
2 On a related analysis, 'the movie is ideal for children' supports 'taking your son to see this movie'; and 'it will be gone tomorrow' supports 'you ought to do so today'. Though each reason now supports a part of the conclusion sufficiently, what they cite is causally unrelated, hence independent (Pearl \& Mackenzie, 2018).
} 
opportune way of forwarding the counter-consideration. This disqualifies the argument as a genuine conduction. Thus, it speaks decisively against viewing $S_{1}$ as capturing what a conduction is. $S_{1}$ rather captures how a conductive pattern may be used $^{3}$

Next, turning to $\mathrm{S}_{2}$, this makes a counter-consideration a third component besides premises or conclusion. Freeman $(1991,173)$ refers to this component as "background material." For Govier, it is an "anti-premise" $(1999,156)$ or a "con factor" (ibid., 171). Jin (2011, $25)$ calls it a "distinctive non-basic component." Hansen (2010) uses 'counter-consideration', as does Govier $(1999,156)$. These distinct terms nevertheless convey a unifying idea, namely that of an element that provides, or that an arguer uses to provide, negative support to the conclusion.

For Freeman, "counterconsiderations [...] do not constitute some additional category of argumentative element" (1991, 174). They rather count as "rhetorically crucial background material" that should be acknowledged "in the context of an argument [, yet] without making them part of the argument" (ibid., 173; his italics). Before an analyst places elements in the background, however, we should ask

3 Comparing this usage with a rhetorical view on conduction, Xie (2017) submits that the function of counter-considerations is "not [to] enhance [a conduction's] justificatory power, but [to increase] its persuasive effect" (Xie, 2017, 6; italics added). Therefore, "a counter-consideration doesn't necessarily mean that the arguer accepts it as a point [that is] relevant to the establishment of the conclusion" (ibid., 5). With reference to the reasoning vs. arguing-distinction, Xie rather regards the usage of a conductive argument as "an act of arguing by which we intend to persuade some other [party] to accept a particular view that we have already reached [in reasoning] and currently hold" (ibid., 18; italics added). Presenting the argument, then, would merely make one's view manifest.

Xie uses 'conduction' to reference acts of arguing "preconditioned with a completed inquiry [that the arguer had already undertaken] about the conclusion by [means of] weighing and balancing" (ibid.; his italics). Our own view is at odds with this. For rather than presupposing it, we understand the inquiry (regarding the conclusion, and proceeding via weighing and balancing) as being completed in or being undertaken as conduction. 
the following: if counter-considerations "may [indeed] be very effective to make manifest that the positive reasons [...] outweigh these negative considerations" (ibid.), then why avoid them as a proper argument part? Here, Freeman owes a reasoned answer, indicating (to us) that background elements are postulated ad hoc.

Govier, Hansen, and Jin likewise submit that counter-considerations are distinct from premises, "because they are not put forward as supporting the conclusion" (Govier, 1999, 156). These scholars agree that, besides premises and conclusion as basic elements, arguments should not contain a third basic element. Alas, a counter-consideration may well be non-basic to argument in general, yet basic to conductive argument in particular. If so, then a third component would be superfluous overall, but permissible in specific arguments - namely conductive ones. All the same, however, this disqualifies $\mathrm{S}_{2}$ as a general analysis.

According to $\mathrm{S}_{3}$, a counter-consideration is a premise after all. This challenges our normal understanding of 'premise' as denoting an exclusively supporting element. For irrespective of whether a counter-consideration targets a supporting premise or the premiseconclusion link, it provides negative support. Jin $(2011,25)$, for instance, traces 'premise' to Aristotle's 'protasis' - a reason one lays down or puts forward - but "include[s] counter-considerations under a stipulative definition of 'premise'." This modification, however, of what 'premise' (and hence 'argument') means ordinarily, is not so innocent. Indeed, accepting counter-considerations as negative premises immediately raises the question whether, and if so how, an argument (claimed as) featuring exclusively negative premises could nevertheless be a good argument? On a product view, after all, a negative premise can hardly enjoy the same status as a positive premise. For what, inferentially speaking, would follow from negative premises alone?

To address this difficulty, we might distinguish two types of premises: positive and negative ones. In good arguments, then, the 
positive type would function on its own, while the negative type would require "help," as it were, from at least one instance of the positive type. Like the introduction of background elements (as per $\mathrm{S}_{2}$ ), however, also this distinction seems ad hoc. For what is the relevant difference between a negative premise and a third component? In brief, $S_{3}$ seems (to us) hardly more plausible than $S_{2}$.

The forgoing, we submit, provides sufficient reason to claim that $\mathrm{S}_{2}$ or $\mathrm{S}_{3}$ leave us with a conceptual "monster." Rather than explain what conduction is, moreover, $\mathrm{S}_{1}$ unduly cites the purpose for using it. We therefore proceed to argue in support of $S_{4}$, and present reasons favoring a dialectical view.

\section{Conductive argument, product view, validity}

\subsection{Overview}

We saw how $S_{1}$ to $S_{3}$ challenge the meaning of both 'argument' and 'counter-consideration'. This section reviews why scholars nevertheless treat conduction on a product view (3.2), explains Wellman's reasons for advocating a dialectical view (3.3), and discusses the evaluation of conductive arguments (3.4), particularly how we can make the claim-to-validity explicit (3.5).

\subsection{Conductive argument on a product-view}

Hitchcock submits that "informal logic studies arguments in the reason-giving [vs. the disputational] sense" (Hitchcock, 2007, 102; see Jin, 2011, 13f.), and refers to a conductive argument as a 'balanceof-considerations argument'. Focusing on its support relation, he treats "each separate consideration as an argument [or premise] supporting the conclusion 'other things being equal'." By contrast, he views "the sum of them as an argument supporting [the conclusion] 'all things considered"' (Hitchcock, 1983, 51). Only the analytical freedom that a product-view offers can motivate viewing each 
consideration as an argument on its own. So rather than admit a product view, Hitchcock indeed requires it.

According to Govier, "[a]n argument is a set of claims in which one or more of them - the premises - are put forward so as to offer reasons for another claim, the conclusion" (Govier, 2010, 1). Particularly conductive arguments, she holds elsewhere, place us "in the territory of 'giving reasons' [...] to support the conclusion" (Govier, 1999, 155). Suggesting that she endorses a dialectical view, Govier observes that "[c]ounter-considerations may, of course, be introduced by critics" (ibid.; italics added). In fact, it is "rather common for arguers themselves to recognize the existence of counter-considerations [...]" (ibid.). Unlike Hitchcock, then, Govier seems to require a dialectical view.

Indeed, the sixth of her nine evaluative questions (aka critical questions) reads: "[w] hat are the counter-considerations put forward by the evaluator or critic that count against the conclusion" (ibid., 170; italics added). Her remaining eight questions, however, squarely reflect a product view. Although she acknowledges a dialectical view, then, it is not clear that she applies it stringently. Rather, hers is a hybrid view, the product component of which is dominant. As with Hitchcock, therefore, we also treat Govier's as a product view.

Hansen observes for conductive argument that "the reasoning, before issuing in a conclusion, takes into account considerations against the conclusion in addition to the reasons or considerations supporting the conclusion" (Hansen, 2010, 33; italics added). Like Govier, he finds that the scholarly discussion has treated conductive arguments mostly as "a social argument, a debate or a discussion, in which there are two disagreeing parties advancing their own positions and arguing against each other" (ibid., 35; his italics). But he rejects this treatment, for it is "not the kind of argument Wellman and Govier have in mind" (ibid., 35).

As Hansen also observes, scholars have predominantly viewed 
conductive argument as a "premise-conclusion kind of argument, typically defined as a set of claims (or propositions) of which one is the conclusion, and the remainder are put forward as reasons in support of the conclusion" (ibid., 35f.). But "if we are wont to individuate arguments on the basis of one-reason per argument," then conductive arguments "appear to be cumbersome unnatural logical kinds," he submits, for they do not feature "one-reason per argument" (Hansen, 2010, 35; italics added). Thus, Hansen agrees that one must find ways besides treating counter-considerations as premises.

Also Jin "focus[es] on the structure of pro and con arguments from a product point of view" $(2011,24)$. He moreover states (misleadingly) that "Wellman adopts a product approach to arguments in general and pro and con arguments in particular" (ibid., 13). Indeed, Jin finds that already the "concept of argument is obviously based upon a product [...] view," such that an argument is "a designated set of propositions, one of which is put forward on the basis of the others" (ibid., 11; italics added). (Below, we give reasons to doubt these claims.)

This, at any rate, is sufficient textual evidence that present-day scholarship acknowledges Wellman's intellectual heritage, and yet finds a product view on conductive argument normal. We proceed to trace Wellman's own view.

\subsection{Why Wellman held a dialectical view}

Some scholars treat an externalized instance of conductive reasoning such that a set of arguments expresses it. This construction manages to retain the ordinary meaning of both 'premise' and 'argument'. For it ingeniously places a counter-consideration that undermines a conclusion, $\mathrm{C}-\mathrm{a}$ counter-consideration that itself originates as part of an argument, $\mathrm{A}$ - into the premise-slot of another argument, $\mathrm{A}^{*}$, that provides support to the conclusion's negation, not $\mathrm{C}$.

A conductive argument shall nevertheless have only one overt conclusion. This constraint presumably motivates Hitchcock's "all- 
things-considered argument" (see Sect. 3.2). For it shall (somehow) sum over the individual arguments-for- $\mathrm{C}$ as well as the argumentsfor-not C (see Sect. 2.3). Could Wellman's own view on conduction reasonably motivate, or at least allow for, such a construction?

As Jin $(2011,11)$ observes (correctly), "Wellman maintains that any argument has three components," viz. premises, conclusion, and "a claim to validity [...] indicat[ing] that the conclusion is thought to follow validly from the premises." Since "the claim to validity is usually implicit and closely related to the evaluation of arguments," moreover, Jin finds that "we can leave it aside when describing the structure of arguments," and can hence treat "premises and conclusions as the [only] basic components of arguments" (ibid; italics added).

Neglecting the third component, however, is exegetically unfair to Wellman, and disregards an important systematic idea. For the element by which "[p]remises and conclusion are held together or unified in the argument" - an element Wellman refers to as the claimto-validity - becomes "explicit in critical judgments directed at arguments" (Wellman, 1971, 90; italics added). The claim-to-validity thus relates to argument evaluation, where implicit components must become overt.

Pointing to the age-old observation typical of enthymematic argument - that argument production can regularly leave the claim-tovalidity implicit - hardly provides a sufficient reason to ignore this claim as a basic argument component. Indeed, Wellman's own use of 'validity' shows that his understanding thereof differs importantly from what an argument-as-product treatment suggests. For "[ $\mathrm{t}] \mathrm{o}$ say that an argument is valid is to claim that when subjected to an indefinite amount of criticism it is persuasive for everyone who thinks in the normal way" (ibid., 90; italics added). Specifically, a valid argument in this sense "usually persuades one who accepts or has its premises, who rejected or doubted its conclusion just before being subjected to the argument, and who thinks through the argument" 
(ibid., 91; italics added). It is in precisely this sense that Wellman claims: "to say that an argument is valid is to claim that $[. .$.$] it is$ persuasive" (ibid., 90; italics added).

For Wellman, a valid-qua-persuasive argument thus entails first accepting the premises while rejecting (or doubting) the conclusion and then accepting the conclusion because of the argument. Temporal succession, a change in acceptance, and its cause, all remain compatible with a product view. Alas, none of these characteristics features in how a product view normally defines valid argument. Wellman's notion of validity, therefore, is hardly that which accompanies a product view normally - namely formal logical validity. Instead, his notion comes much close to the RSA-criteria (relevance, sufficiency, acceptability) of informal logic.

Moreover, nothing in Wellman's writing forces us to interpret the "indefinite amount of criticism"-condition as demanding an exclusively rhetorical reading of argument validity. For Wellman uses 'criticism' to mean "a process of thinking about and discussion of the argument," where "[a] process $i$ s criticism of the argument because it serves to test its claim to validity" (ibid., 92; italics added). Though one may interpret 'process of thinking' as subject-internal, the term 'discussion' we must read as a denoting a social and interactive process.

This interactive sense, indeed, does seem primary. For Wellman holds that:

[s]aying that an argument is valid may be a way of announcing that one is prepared to defend it, or challenging all hearers to refute it if they can, or reaffirming one's acceptance of the argument after criticism, or conceding that one has at last accepted the argument under critical pressure, or proclaiming that one has defended it successfully. (ibid., 98; italics added) 
Rather than a product view, this unambiguously suggests a dialectical view. What may have sustained a contrary impression is Wellman's use of 'truth'. For his use seems compatible with understanding truth in the (ontological) sense of an objective fact. His use of 'validity', however, runs "parallel to [his] definition of truth" (ibid., 101). And Wellman finds that true is what "will be believed by everyone who thinks in the normal way after an indefinite amount of criticism" (ibid., 99; italics added). So Wellman uses 'true' in the audience-relative sense that Perelman adopts for the universal audience (Perelman \& Olbrechts-Tyteca, 1969; see Fisher, 1986; Tindale, 1999; 2004).

Functionally, Wellman's claim-to-validity lets one transition from premises to a conclusion. Like Toulmin's (1958) warrant, this claim is often - even normally_implicit, and must become explicit only under critical scrutiny. Both Wellman's claim and Toulmin's warrant, then, let us arrive at a conclusion from premises. Toulmin simply does not treat conduction as a separate category. (For a recent product-treatment of warrants in conductive argument, see Freeman $(2011).)^{4}$

When Wellman stipulates that "everyone who thinks in the normal way" will accept the conclusion, then-like Bacon (1605) does

\footnotetext{
${ }^{4}$ Freeman (2011) suggests that the warrant of conductive arguments has the form: ' $\Phi \mathrm{x}_{1}, \mathrm{x}_{2}, \ldots, \mathrm{x}_{n}$, therefore ceteris paribus, $\psi \mathrm{x}_{1}, \mathrm{x}_{2}, \ldots, \mathrm{x}_{n}$ ' $(2011,135)$. We can thus understand this warrant as the inference rule: "[f]rom: $\Phi \mathrm{x}_{1}, \mathrm{x}_{2}, \ldots, \mathrm{x}_{n}[\ldots]$ infer ceteris paribus: $\mathrm{Cx}_{1}, \mathrm{x}_{2}, \ldots, \mathrm{x}_{n}$ " (ibid., 129). He moreover introduces a dialectical tier of conductive argument, and holds that rebuttals and counter-rebuttals must be considered (ibid., 138-144). The approach's product-orientation may explain the unnaturalness of warrants such as: "[a] cold front moving at $20 \mathrm{mph}$ in the direction of [location] $x$ is 60 miles from $x \&$ will dissipate before it reaches $x \&$ will form again before it reaches $x$," leading to the conclusion that, ceteris paribus, "it will start raining at $x$ in approximately three hours." Freeman's main aim, after all, is to check the warrant's reliability - for which one should first "determin[e] its epistemic type," then see "whether proper backing for that warrant is available in this case." By contrast, our favored view "disassembles" this complex warrant, by constructing a dialectical situation between argumentative parties, resulting in a reconstruction of several arguments, rather than one.
}

(C) Shiyang Yu. Frank Zenker. Informal Logic, Vol. 39, No. 1 (2019), pp. 32-69 
with his idolatry - he invokes "a uniformity of persuasiveness that is usually there in the thinking of most men on any given sort of argument" (Wellman, 1971, 97; his italics). The passage is worth quoting in full:

By a way of thinking I mean something more like a tendency to be persuaded by some sorts of arguments and not by other sorts [...]. $[\mathrm{T}]$ he claim to objective validity presupposes that there is something like a normal way for the human mind to work. This normality is not identical with the consensus of present agreement or the present persuasive force of various arguments but by a uniformity of persuasiveness that is usually there in the thinking of most men on any given sort of argument. Normality does not require complete uniformity of all men but only of most men, and it must be determined separately for each kind of argument. It is not necessary that all men think alike in all reasoning, but only that most men are similarly persuaded or unpersuaded by any given sort of argument. If there were not in fact such a psychological uniformity in the human mind, it would be pointless to claim anything like objective validity. (Wellman 1971, 96f.; italics original)

In brief, Wellman's normal way arguably is the reasonable way that persuades the universal audience. Alternatively, using Toulmin's focal term, the claim-to-validity of a conductive argument is a warrant that the universal audience accepts as reasonable.

\subsection{Evaluating conduction as practical defeasible reasoning}

On textual evidence, we saw that Wellman treated conduction on a dialectical view. It is a truism, moreover, that an argumentative process constituting conduction produces conductive arguments-asproducts. Indeed, there is no obstacle to representing a conductive argument as a product, or as a dialectical process. Both views are compatible. 
A systematic reason to nevertheless favor a dialectical over a product view cites conduction as a practical reasoning mode. Unlike the theoretical mode, which pursues truth, the practical mode governs decision-making contexts pivoting on the acceptability of claims-to-action such as "X should (not) do Y" (Kenny, 1996, 65; Kock, 2007, 94; 2009, 73). ${ }^{5}$ In such contexts, resource limits and broadly human constraints (cognitive or other) place hard limits on our ability to consider all relevant evidence. Particularly new evidence regularly becomes available while the decision-making process unfolds.

This renders deductive logic a cumbersome reconstructive tool and makes (formal) logical validity implausible as an evaluative criterion since deductive logic is monotonic (Woods, 2013, 67). As such, it reliably tests whether a stable premise-set entails a conclusion with logical necessity. ${ }^{6}$ Given premise-revision (AGM, 1985),

\footnotetext{
5 Wellman holds that "[p]erhaps the most striking feature of all the examples of conduction I have given is that they all deal with particular cases," because "each derives a conclusion about an individual act or object from information about that same act or object," and "the conclusion of a conductive argument is a particular judgement" $(1971,52)$. We are inclined to restrict conduction to practical reasoning, or practical argument. After all, Wellman observes that "[a] few ethical arguments that fall into neither of the two traditional categories [viz. deduction and induction] are the following: You ought to [...]" (ibid., 51). This relates conduction with practical argument. Rather than precluding other modes of reasoning or argument besides the practical, however, we merely suggest that this restriction fits well with our own model in Sect. 4.8.

${ }^{6}$ Aristotelian scholarship has it that "a deduction is an argument in which, certain things being laid down, something other than these necessarily comes about through them" (Aristotle, 1984, Vol. 1, Topics 1.1, 100a25-27, italics added; see van Eemeren et al., 2014, 63). According to what modern logic calls deductive inference, by contrast, the semantic content of a premise set from which a conclusion, C, does validly derive deductively will contain C's content fully (content preservation). The monotonicity of deductive inference, moreover, implies that premises validly entailing $\mathrm{C}$ deductively continue to entail $\mathrm{C}$ upon adding $a d d i$ tional premises to this set. Therefore, if information strictly besides the premises' content shall "come about through them"- in ways we can model logically-then we deal with an inductive, content enlarging inference.
}

(C) Shiyang Yu. Frank Zenker. Informal Logic, Vol. 39, No. 1 (2019), pp. 32-69 
however, deductive logic does not readily model the defeasible inference (Pollock, 1987) that a conduction is.

Absent a worked-out logic of "third kind-reasoning" (Woods, 2013), therefore, our reconstructive tool is inductive logic (Spohn, 2012), which specifies important aspects of the RSA-criteria (Gooden \& Zenker, 2018). It evaluates if evidence (the premise set) comparatively supports a hypothesis (the conclusion) to a degree sufficiently larger than the degree to which the premises support the conclusion's negation. Though formally well defined (e.g., Strevens, 2017), this comparison is objectively meaningful only if we may assume frequencies of repeating event tokens (aka physical probabilities).

Practical arguments, by contrast, pivot on the probability cum utility we assign to single events, whether these in fact occur, or not. As we now employ inductive logic to reconstruct a given practical argument (e.g., Korb, 2004; Oaksford \& Hahn, 2004; Zenker, 2013b; Godden \& Zenker, 2018), its comparative evaluation pivots on two quantities (here assuming stable utilities): the prior probability of the conclusion and the likelihood of the premises given the conclusion. Because we lack an objective (physical) basis that both quantities could "mirror," however, each must remain subjective, and so can be controversial (Witte \& Zenker, 2017). In brief, we lack an objective handle, as it were, to evaluate the argument.

To give an example, consider whether "your lawn needs cutting" does, or does not, defeat "you ought to take your son to the movies." The evaluative result pivots on the comparative importance (Zenker, 2011) that you and I assign to a well-cut lawn vs. a well-educated son. Since the example construes both options as exclusive alternatives, moreover, the lawn — as the reader will readily agree-is normally (much) less important. That, indeed, is the example's point.

Appreciating this point illustrates why Wellman speaks of "persuasion under normal conditions." As we saw, if arguer A's subjective importance assignment alone can defeat arguer B's assignment, 
then we lack an objective handle to evaluate the argument. Further, notice that the example establishes its conclusion without referencing a moral value such as education, or mentioning that education ranks higher than a well-cut lawn. It rather suffices that arguers normally find it unreasonable to rank one's lawn above one's son. So an explicit value hierarchy is dispensable.

Unless there are overt reasons to assume otherwise, then, the claim-to-validity can stand proxy for the value hierarchy that makes this claim persuasive if normal conditions obtain. Under non-normal conditions, by contrast, this ranking may well be different. For instance, if your son had watched the movie already; if you prepared your property for today's sales event; or if your son were grounded. In this sense, then, conductive arguments are defeasible.

A dialectical view accounts for the defeasibility of practical arguments by listing both the proponent's supporting reasons for a conclusion and the opponent's (undercutting or undermining) reasons against it. A dialogue tableau, for instance, lets us represent how pro and con reasons relate to the conclusion (Barth \& Krabbe, 1982). As we evaluate the argument, the validity of $m y$ conclusion does also here depend only on whether you accept how I arrive at it from premises we share. (This makes argument validity inter-subjective.) Compared to using a tableau, therefore, inductive logic adds reconstructive precision. As an evaluative tool, however, inductive logic is at most as defensible as a dialectical view.

In summary, Wellman's motivation for a dialectical view was to highlight the argumentative process of "attacking and defending and explaining beliefs" (Wellman, 1971, 100). (This may be why argumentation scholars attend to his work.) Specifically, Wellman viewed truth as the property of "a claim to be tested within a process that has no limit" (ibid.; his italics). This process's salient features are arguers' idiosyncratic ways of providing reasoned support for, or resistance to, such claims. What Wellman highlights, then, is the sub- 
jective or personal aspect of testing a claim with respect to argumentative validity.

\subsection{Making it explicit}

This personal aspect of validity (partially) explains why Wellman viewed the claim-to-validity as implicit until we criticize the argument. Nothing in Wellman's writing indicates (to us) that he evaluated conductive argument other than by assuming that arguers assign degrees of importance to reasons and counter-considerations, degrees that represent why arguers accept or reject a conclusion. If so, then what may separate you from accepting how my claim-to-validity lets me transition to a preferred conclusion is your low evaluation of this claim. As a matter of contingent fact, moreover, your evaluation of my claim may more closely align to what persuades normally. Conversely, we may view your claim-to-validity-letting you transition from shared premises to a conclusion opposing mine-as standing-in for the value hierarchy that grounds your claim's persuasiveness. Thus, a claim enjoying persuasiveness ceases to presuppose an explicit value hierarchy. Functionally, your personal evaluation of the claim suffices.

This personal aspect, as we now show, one can make explicit. As a necessary (but perhaps insufficient) condition to complete a round of argumentation, we propose that two arguers must (i) voice a conclusion, $\mathrm{C}$, or respectively its negation, not $\mathrm{C}$ (or some conclusion $\mathrm{C}^{*}$ that entails not $\mathrm{C}$ ); and (ii) both must forward at least one reason for their respective conclusions.

To motivate this condition, we restate Wellman's example as a dialogue. Given a proponent/opponent-pair, the argument-as-product: "Although your lawn needs cutting, you ought to take your son to the movies because the picture is ideal for children and will be gone by tomorrow" (Wellman, 1971, 57) thus becomes:

1. [Proponent's statement of $\mathrm{C}$, and first reason-for-C] You ought to take your son to the movies, because the picture is ideal for children. 
2. [Opponent's statement of not $\mathrm{C}$, and reason-for-not C] It is not the case that you ought to do so today, because your lawn needs cutting.

3. [Proponent's second reason-for-C, and restatement of $\mathrm{C}$ ] But the movie will be gone by tomorrow, so you ought to go today.

If the proponent's conclusion prevails, say, then the opponent may either stop or continue arguing. Either way, the round of conductive argumentation is now complete. The necessary implicit element that has the proponent prevail is the following claim-to-validity: 'the movie being gone tomorrow is a comparatively (or decisively) more important reason than the lawn needing a cut'. The notion 'comparative importance' thus appears in the reconstructed claim-to-validity.

Unless we can offer criteria to evaluate the claim-to-validity other than personally, evaluating conductive arguments remains challenging. In the absence of a well-established objective value hierarchy (Zenker, 2013a), indeed, we can only point — with Wellman — to an indefinite process of criticism under normal persuasive inclinations.

\section{The structure of conduction}

\subsection{Overview}

We review current ways of diagramming a conductive argument (4.2 to 4.7), but in each case find minor fault with how reasons converge, and with how scholars spell out, and where they locate, the on-balance-principle. We propose a structure that shall remedy these faults (4.8 and 4.9), then conclude (Sect. 5).

\subsection{Govier (2010)}

In Govier's (2010) diagram (Fig. 2), premises and conclusion are numbered (' 1 ' is the conclusion), a straight arrow represents a proreason's supporting effect, and the "wavy" variant stands for a counter-consideration's undermining effect. A bar across a wavy line 
represents that the respective premises "count against the conclusion rather than for it" Govier (2001, 396; see ibid., 355f.). ${ }^{7}$

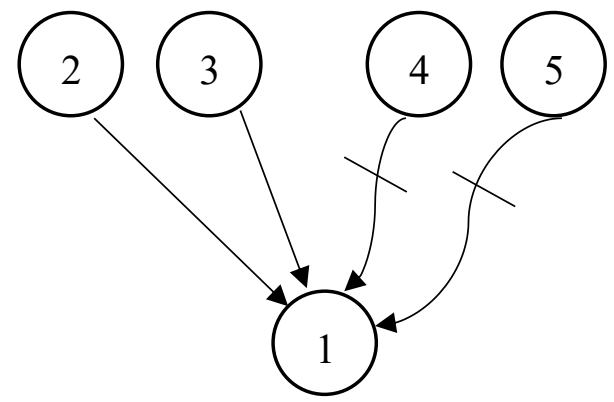

Fig. 2 : Govier's structure of conduction

Fig. 2 is not only a pattern of positive (pro-reason-based) support to which the counter-considerations merely attach. It also includes the negative support of counter-consideration-based support. For the "premises [in their entirety] support, or are put forward as supporting, the [same] conclusion convergently" (Govier, 1999, 156; her italics). Accordingly, her evaluative question reads: "How strong is each of these counter-considerations [by itself] as a reason against the conclusion?" (ibid., 170; italics added).

Like Jin $(2011,26)$, who adopts this, we too understand a convergent structure as comprising both support and opposition. Thus, 'convergent' presupposes that premises are mutually independent, where the linked vs. convergent support-distinction specifically traces if reasons are mutually independent given the conclusion, $\mathrm{C}$. Crucially, only if $n$ reasons in fact are mutually independent does

\footnotetext{
7 Presumably, Govier's 'count against' is not synonymous with 'outweigh.' For she uses "wavy lines and a bar, to indicate that they [the reasons] count against the conclusion rather than for it" $(2001,396)$. From Govier $(2010,366)$, we understand that her diagrams "indicat[e] any counterconsiderations with a wavy line and bar." So Govier once uses wavy lines alone $(2010,355)$, and once wavy lines with bars (ibid., 366), but fails to clarify which difference the bars make.
} 
retracting one of them (rightly) leave unaffected the support that $n-1$ reasons provide for C. In Fig. 2, the numbers 2-5 thus indicate independent reasons. Yet, this fails to address the case of linked reasons, where retracting one of $n$ reasons affects the support that $n-1$ reasons provide. ${ }^{8}$ (We return to this in Sect. 4.4.)

Like Wellman, Govier holds that "we commit ourselves to the judgement that, on balance, the pros outweigh the cons, and do so to a sufficient degree [in the sense] that there are good grounds for the conclusion [C]" (ibid.; her italics). However, Fig. 2 lacks a representational element that does the outweighing. So how we arrive at the focal contention - that $C$ receives (significantly) more support than not $C$-remains without representation.

\section{$4.3 \operatorname{Jin}(2011)$}

For this reason, Jin (2011) modifies Fig. 2. He uses a turnstile-like symbol to indicate that pro-reasons outweigh counter-considerations, which he groups into boxes (Fig. 3).

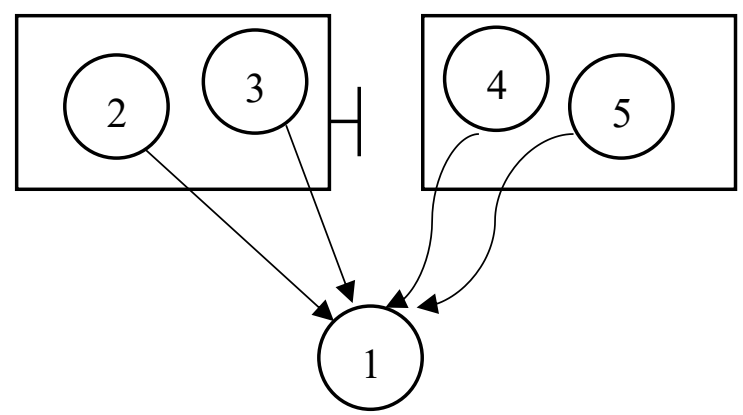

Fig. 3 : Jin's structure of conduction

8 Both Wellman's and Govier's definition of conduction-according to which "one or more premises are put forward as reasons supporting a conclusion" (Govier, 1999, 155) — hardly necessitate a convergent structure. As Ennis $(2004,35)$ observes, moreover, "[Govier's] convergence requirement seems unduly narrow and difficult to apply." (It even lacks a demand that reasons be relevant to the conclusion.) According to Blair $(2011,4)$, finally, Govier's $(2001,392)$ version in fact rejects Wellman's first pattern of conduction, and provides but a truncated instance of his second pattern.

(C) Shiyang Yu. Frank Zenker. Informal Logic, Vol. 39, No. 1 (2019), pp. 32-69 
This "structure at the level of the connection among PC, CC and K [pros, cons, and conclusion]" (ibid., 26), he submits, is quasi-linked because positively and negatively supporting reasons operate together, and both kinds are indispensable to a conductive argument. At one analytical level, then, pro-reasons quasi-link to con-reasons. At another such level, however, Jin identifies "a convergent structure [, namely] at the level of the relation between the individual members of PC or CC and K" (ibid.). This second level, then, is where the outweighing happens.

Both levels together "represent pictorially how single considerations are independently relevant to the conclusion" (ibid., 17). This holds in the required sense that, were "either of them [...] removed, [then] the relevance to K of the rest would be unaffected" (ibid., 23). The (groups of) pro and con reasons thus link to each other, while individual group-elements nevertheless support, or undermine, the conclusion independently. Functionally, then, we deal with a mixed structure.

\subsection{Linked reasons}

Slightly varying Wellman's focal example allows us to exemplify two pro-reasons that are arranged in a properly linked structure. (We could construct an analogous example with con-reasons.)

Although your lawn needs cutting, you ought to take your son to the movies because the picture is ideal for those underage, and your son is underage.

The pro-reasons' joint relevance-for- $\mathrm{C}$ here is arguable, as is the degree of support that $\mathrm{C}$ would enjoy. (Both pro-reasons together seem not to support $\mathrm{C}$ significantly more than not C.) Nevertheless, this is a conductive argument. Indeed, to understand that a conductive argument need not (exclusively) feature mutually independent reasons, 
it suffices to see that each pro-reason may be irrelevant to $\mathrm{C}$ by itself, yet may become relevant if joined to other reasons. This is the case here. So a conductive argument may instantiate either a convergent or a linked structure.

\subsection{Hitchcock (1983)}

Hitchcock's $(1983,51)$ structure seemingly permits the linked relation (between pros and cons) that Jin's structure did not offer (Fig. 4). He suggests to "introduce each consideration by a plus sign if it is positive and a minus sign if it is negative, and by bracketing the total as supporting the conclusion" (ibid.). In Fig. 4, reasons 1, 2 and 4 thus are positive considerations; 3 is negative, and 5 is the conclusion.

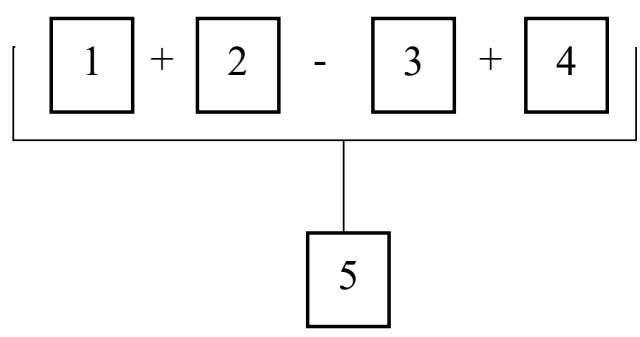

Fig. 4 : Hitchcock's structure of conduction

Hitchcock calls reasons 1 to 4 "independent but mutually enhancing reasons for a conclusion" (ibid.; italics removed), as compared to the support that a single reason provides alone. Also his structure, then, is convergent-like Govier and Jin had it. So Fig. 4 too fails to address the case of linked reasons. As with Govier's diagram, moreover, Hitchcock's lacks an overt "outweighing consideration." 


\subsection{Hansen (2010)}

Jin's (2011) implicit premise - that the pros outweigh the cons - we already find in Hansen $(2010,40)$, who also offers a two-level structure. The first level houses the inference from ' $\mathrm{P}_{1}, \mathrm{P}_{2}$ ' and the implicit 'on-balance premise' to the conclusion ' $\mathrm{K}$ even though $\mathrm{CC}_{1}+\mathrm{CC}_{2}$ '. The second level houses the inference from ' $\mathrm{K}$ even though $\mathrm{CC} 1+\mathrm{CC} 2$ ' to ' $\mathrm{K}$ '. It is a truth-functionally valid inference, namely a "simplification from a sentence of the form ' $p$ even though $q$ ' to ' $p$ "' (ibid.; his italics) (see Fig. 5).

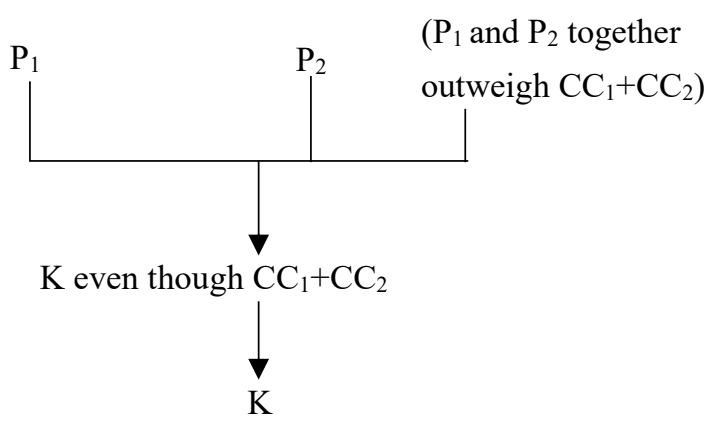

Fig. 5: Hansen's structure of conduction ${ }^{9}$

The diagram conveys clearly that the premises jointly outweigh the counter-considerations. Insofar as a given evaluation of counterconsiderations can change, or insofar as new counter-considerations may arise. Moreover, the inference from $p$ outweighs $q$ to $p$ even though $q$ is defeasible (Hansen himself does not use this term). His structure thus combines a defeasible with a deductive inference.

The on-balance principle- $\mathrm{P}_{1}$ and $\mathrm{P}_{2}$ together outweigh $\mathrm{CC}_{1}+\mathrm{CC}_{2}-$ Hansen treats as an implicit element, rejecting the idea that counter-considerations qualify the conclusion. Since counter-

\footnotetext{
9 Hansen does not explain why he uses both 'and' and '+'. We take it, both strings stand for logical conjunction.
} 
considerations operate at the second level only, this makes ' $\mathrm{K}$ even though $\mathrm{CC}_{1}+\mathrm{CC}_{2}$ ' an intermediate conclusion. The on-balance-principle thus counts as a premises; the main conclusion is the single element $\mathrm{K}$. The argument therefore has two inference steps: first, ${ }^{\mathrm{C}} \mathrm{P}_{1}$, $\mathrm{P}_{2}$ ', ' $\mathrm{P}_{1}$ and $\mathrm{P}_{2}$ together outweigh $\mathrm{CC}_{1}+\mathrm{CC}_{2}$ '; hence ' $\mathrm{K}$ even though $\mathrm{CC} 1+\mathrm{CC} 2$ '; second, hence ' $\mathrm{K}$ '.

Though the second inference is deductively valid, this does not make it a pragmatically valid inference. In relevant contexts, one would not immediately reason from ' $\mathrm{K}$ even though $\mathrm{CC}_{1}+\mathrm{CC}_{2}$ ' to ' $\mathrm{K}$ ' - at least not unless one had first answered positively that $\mathrm{K}$ 's "benefits" do, on balance, outweigh what "harms" $\mathrm{CC}_{1}$ and $\mathrm{CC}_{2}$ harbor. This makes the on-balance-principle a crucial pragmatic element. Rather than establish that principle's subjective evaluation, however, the deductive inference reports it. Though Hansen's structure makes the necessary pragmatic element desirably explicit, then, we can slightly improve its form.

\subsection{Getting to doing}

According to Wellman, as we saw, the element that in a conductive argument "gets us" from premises to conclusion is the claim-to-validity. This claim we did state as '.. is a comparatively (decisively) more important reason than...' The claim semantically entails 'the pros outweigh the cons' - which Hansen treated as an implicit premise.

In a realistic decision-making context, if the pros $d o$ (decisively) outweigh the cons, then we should presumably enact the conclusion that the pros support. Oddly, now, the premise 'the pros outweigh the cons' does not get us to doing. For it lacks linguistic reference to action. Instead, the wording remains intellectual. A suitably stronger version of this premise should not only reflect that persuasion without action is impotent; it should also respect Wellman's idea of persuasion under normal conditions. Given any accepted premises, moreover, we transition to a conclusion most directly, and firmly, if 
our warrant renders this transition an instance of deductive inference. As a revised premise, therefore, we propose: "if the pros outweigh the cons, then act as the more supported conclusion says."

\subsection{Upshot}

Each of the four conductive structures, above, we could improve. Three of these structures failed to represent the on-balance-principle, and the fourth failed to make the very conclusion derivable that a practical argument requires.

A more adequate diagram of conduction in Wellman's sense, moreover, should account for two basic cases. First, if a standpoint is yet in need of reasoned support, then conductive reasoning leads from the conclusion to the premises. We diagram this supportfinding variant below (Fig. 6). In the conclusion-challenging variant, by contrast, arrows point in the opposite directions (see Sect. 4.9).

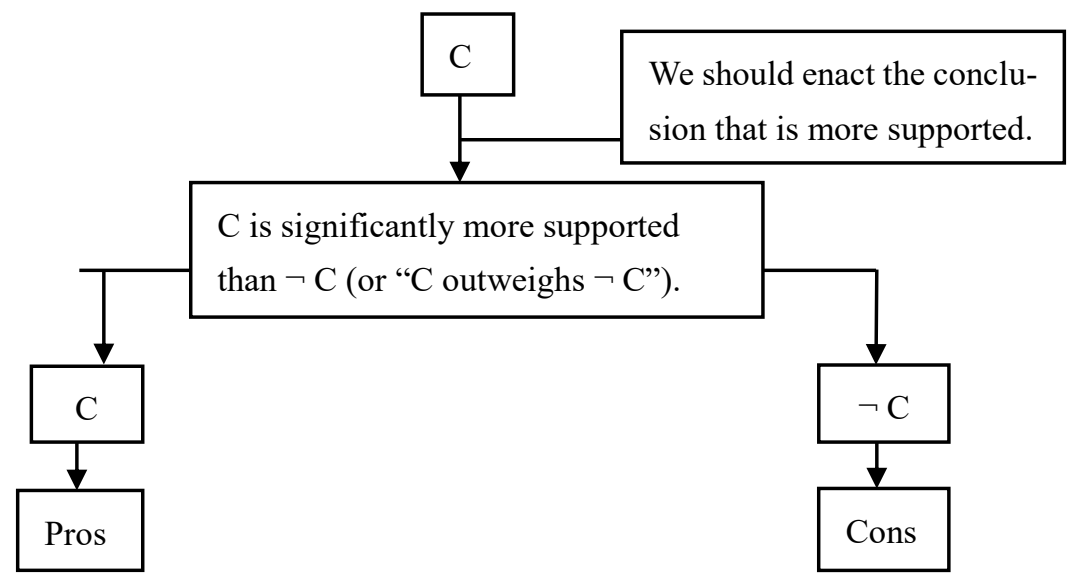

Fig 6. Conduction in Wellman's sense, support-finding variant

This structure combines two analytical levels. The upper-level houses the pragmatic argument schema 'we should enact the conclusion that is more supported'; the lower level cites that ' $\mathrm{C}$ is (signifi- 
cantly) more supported than not $(\neg)$ C' because the pro-reasons outweigh the con-reasons. ${ }^{10}$

Wellman was aware of the limited sense in which, given one raises the claim, an outweighing conclusion is, in fact, more supported. He observes that one determines "the weight of objects by hefting them in one's hands" (Wellman, 1971, 58). Using stones as a metaphor for reasons, he submits, one could at most weigh "two small piles" simultaneously. Hence, one must "lift the stones [i.e., the reasons] in each pile one after the other in order to estimate their total weight" (ibid.; italics added). Translating out from the metaphor, then, "there are limits to the number of considerations one can hold together in [one's] mind at any single moment" (ibid.).

Wellman indeed precludes that we can place pro- and con-reasons on a scale to calculate the support-difference by weighing them. For "there is no unit of logical force in which to do the calculation" (ibid., 57). Not only would this be "too mechanical a process," he submits, it also fails to guarantee- notice his aiming for objectivity - that "everyone read[s] off the result in the same way" (ibid., 58).

In sum, Wellman denies readily available, objective criteria for a weighing of reasons takes our reasoning capacities to constrain the weighing, and admits that human sentiment may influence it. Because we too view conduction primarily as a process that lets arguers continue debating, we proceed to consider its defeasibility.

\footnotetext{
10 Van Laar (2014, 270f.; italics removed) challenges the wording "the supporting considerations 'outweigh' the counter-considerations." He instead opts for "[i]t is not the case that if your counterconsideration $\mathrm{C}$ is true (acceptable), [then] my thesis T (or connection premise) [i.e., our C] is false (indefensible)" (ibid., 270). One alleged benefit of this new wording is to arrive at "a continuum of [argument] strengths" (ibid.). A second alleged benefit is that the opponent can "critically test the proponent's claim" (ibid., 271). However, that some reasons outweigh other reasons continues to explain why a thesis can be defensible although a counterconsideration is true or acceptable. We do share the critical attitude, moreover, but the second benefit hardly arises in virtue of new wording alone.
} 


\subsection{Defeasibility}

By examining and challenging a conductive reasoning, an opponent may cast doubt upon and perhaps defeat a proponent's conclusion. To support the opponent's own preferred conclusion, she can add new considerations, or cast doubt upon the reasons or upon the onbalance-principle. This makes pro- and con- reasons defeasible. ${ }^{11}$ The entire conduction, then, is defeated only if the current conclusion changes to one the opponent favors.

Though it is natural to ask "how do we decide which conclusion prevails?", we find an answer goes beyond what argumentation scholarship should offer. It is nevertheless clear that, even if a prevailing conclusion changes, then the first level premise- - "we should enact the conclusion that is more supported"-remains acceptable. For we cannot criticize it on rational grounds. Rather, a new on-balance principle must now become more acceptable than the original one-namely ' $\neg C$ is (significantly) more supported than $C$ '. We saw that arguers can make this principle explicit, and then criticize it. Applied to Wellman's example, defeat thus implies establishing "taking your son to the movie is (decisively) less supported than cutting your lawn," which implies "it is not the case that you ought to take your son to the movies."

\footnotetext{
11 In response to Adler (2013) challenging the possibility of conductive argument, Blair (2016) observes that "Adler's dismissal of conductive arguments relies on a misreading of the term "non-conclusive;"' and that "as a result, his refutation fails" (ibid., 109). Reacting to Blair's observation, Walton and Gordon $(2015,530 \mathrm{f}$.) find that "[c]onductive arguments [...] certainly do seem to be defeasible, and if defeasibility implies inconclusiveness, in Adler's sense of the term, then Blair is certainly right to reject Adler's rejection of conductive arguments." Selinger and Koszowy $(2016,233)$ specify a "list of requirements collected by Walton and Gordon [2015] that informal logic has to meet." A central item is to "recognize the degrees of acceptability of an argument's premises and conclusion" (ibid.), so as to "compare the strengths of arguments assigned to all considered options" (ibid., 228). They too stress the "absence of a uniform standard for the evaluation of pro against con arguments" (ibid., 232).
}

(C) Shiyang Yu. Frank Zenker. Informal Logic, Vol. 39, No. 1 (2019), pp. 32-69 
In contrast to Sect. 4.8 , if we challenge (rather than construct) a conductive argument, our reasoning proceeds in the opposite direction to Fig. 6. Among others, an opponent who challenges a conclusion must examine the current argument for its weaknesses, and then add new reasons or attack existing ones. In Wellman's example specifically, the conclusion changes only if we establish its complement: 'It is not the case that...'. So the direction of reasoning is bottom-up (Fig. 7).

Defeating this argument requires diminishing the degree to which the pro-reasons support $\mathrm{C}$, thereby increasing support for $\neg \mathrm{C}$. For instance, the opponent could diminish the support that (1) ('The picture is ideal for children and will be gone by tomorrow') provides to $\mathrm{C}$, or deny one or both of the reasons (2): ideal kid-flic; gone tomorrow). Increasing support for $\neg \mathrm{C}$ is analogous (3) and (4). As this process unfolds, opponent and proponent change roles with each new round. The outcome thus depends on whether one side accepts defeat or continues arguing.

You ought to take your son to the movies

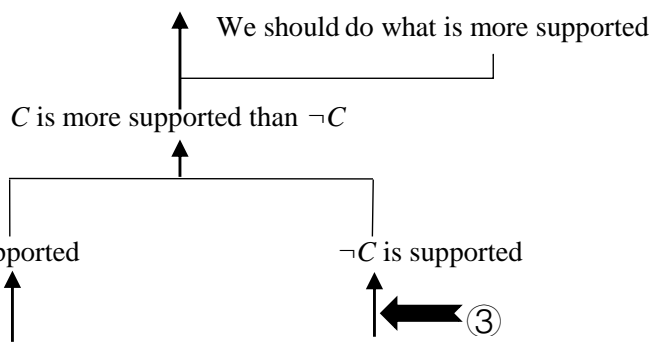

(1)

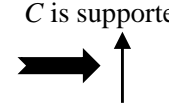

(2) $\longrightarrow$ The picture is ideal for children

The lawn needs cutting (4) and will be gone by tomorrow

Fig. 7 Conduction in Wellman's sense, conclusion-challenging variant, where bold arrows reflect points of attack

Finally, an anonymous reviewer (rightly) notes there is irony in our dialectical treatment of conduction ending with diagrammatic tools that fit a product view. In order to obtain a global view on what conduction is, we submit, a process view serves us best. By contrast, 
to study a conductive argument's individual parts, and its two variants, we can place the product view alongside the process view.

\section{Conclusion}

We reviewed contemporary approaches to conductive argument, provided systematic reasons to favor a dialectical view, and gave exegetical reasons that this was Wellman's own view. Yet, none of these reasons excludes a product view, or makes it "wrong."

A conduction as portrayed consists of reasons that reflect a current discussion-state among parties who hold incompatible standpoints on a practical matter that one must resolve by decision. According to Wellman, moreover, the scope is restricted to argumentation among interlocutors of normal suasory inclination.

The crucial element that lets arguers accept or reject a conclusion based on premises is Wellman's claim-to-validity. It expresses what Toulmin calls a warrant, particularly a warrant that Perelman and Olbrechts-Tyteca's universal audience can accept. We treated the claim-to-validity as a defeasible warrant that stands-in for a value hierarchy grounding the claim's persuasiveness. Analysts can, indeed they should, make this claim explicit by using the notion comparative importance.

Besides offering an improved diagram, we distinguished a support-finding variant and a conclusion-challenging variant of conduction. The former applies as we construct such arguments, the latter as we exploit their defeasibility. A product view generally highlights the former variant to generate a conductive argument; a dialectical view highlights the latter to explain conduction as a lived process.

Acknowledgements: For valuable comments on earlier versions of this manuscript, we thank Minghui Xiong as well as two anonymous reviewers for this journal. S.Y. acknowledges support from the Argumentation Studies in Ancient China project (Grant No. 17GZGX23) and the International Program for Ph.D. Candidates at Sun Yat-Sen University. F.Z. 
acknowledges an Understanding China-fellowship from the Confucius Institute (HANBAN), as well as funding from the Ragnar Söderberg Foundation, the Volkswagen Foundation (No. 90,531), and the European Union (COST Action CA17312).

\section{References}

Adler, J.E. 2013. Are conductive arguments possible? Argumentation 27: 245-257.

Alchourrón, C.E., Gärdenfors, P., and Makinson, D. 1985. On the logic of theory change: Partial meet contraction and revision functions. The Journal of Symbolic Logic 50(2): 510-530.

Aristotle. 1984. The Complete Works of Aristotle. The Revised Oxford Translation (ed. J. Bames.). Princeton: Princeton University Press.

Bacon, F. 1605. The Advancement of Learning. London: Printed for Henrie Tomes.

Barth, E.M., and Krabbe, E.C. 1982. From Axiom to Dialogue: A philosophical Study of Logics and Argumentation. Berlin and New York: Walter de Gruyter.

Blair, J.A. 2011. Conductive reasoning/arguments: A map of the issues. In J.A. Blair, and R.H. Johnson (eds.), Conductive Argument: An Overlooked Type of Defeasible Reasoning (pp. 1-9). London: College Publications.

Blair, J.A. 2013. Are conductive arguments really not possible? In D. Mohammed, and M. Lewiński (eds.), Virtues of Argumentation. Proceedings of the 10th international conference of the Ontario Society for the Study of Argumentation (OSSA) (pp.1-13). Windsor, ON: OSSA.

Blair, J.A. 2016. A defense of conduction: A reply to Adler. Argumentation 30: 109-128.

Ennis, R. 2004. Applying soundness standards to qualified reasoning. Informal Logic 24: 23-39.

(C) Shiyang Yu. Frank Zenker. Informal Logic, Vol. 39, No. 1 (2019), pp. 32-69 
Fisher, W.R. 1986. Judging the quality of audiences and narrative rationality. In J. L. Golden, and J. J. Pilotta (eds.), Practical Reasoning in Human Affairs. Studies in Honor of Chaïm Perelman (pp. 85-103). Dordrecht: Reidel.

Fisher, T. 2011. Weighing considerations in conductive pro and con arguments. In J.A. Blair, and R.H. Johnson (eds.), Conductive Argument: An Overlooked Type of Defeasible Reasoning (pp. 86-103). London: College Publications.

Freeman, J.B. 1983. Logical form, probability interpretations, and the inductive/deductive distinction. Informal Logic 5: 2-10.

Freeman, J.B. 1991. Dialectics and the Macrostructure of Arguments: A Theory of Argument Structure. Berlin and New York: Foris Publications.

Freeman, J.B. 2011. Evaluating conductive arguments: Critical questions in light of the Toulmin model. In J.A. Blair, and R.H. Johnson (eds.), Conductive Argument: An Overlooked Type of Defeasible Reasoning (pp. 127-144). London: College Publications.

Godden, D., and Zenker, F. 2018. A probabilistic analysis of argument cogency. Synthese 195(4): 1715-1740.

Govier, T. 1999. The Philosophy of Argument. Newport News, VA: Vale Press.

Govier, T. 2001, 2005, 2010. A Practical Study of Argument $\left(5^{\text {th }}, 6^{\text {th }}\right.$ and $7^{\text {th }}$ eds.). Belmont, CA: Wadsworth/Thomson.

Hansen, H.V. 2010. Notes on balance-of-considerations arguments. In J.A. Blair, and R.H. Johnson (eds.), Conductive Argument: An Overlooked Type of Defeasible Reasoning (pp. 31-51). London: College Publications.

Hitchcock, D. 1983. Critical Thinking: A Guide to Evaluating Information. Toronto: Methuen. 
Hitchcock, D. 2007. Informal logic and the concept of argument. In D. Jacquette (ed.), Philosophy of Logic (pp. 101-131). Amsterdam: Elsevier B. V.

Jin, R. 2011. The structure of pro and con arguments: A survey of the theories. In J.A. Blair, and R.H. Johnson (eds.), Conductive Argument: An Overlooked Type of Defeasible Reasoning (pp. 10-30). London: College Publications.

Johnson, R. 2011.The relationship between pro/con and dialectical tier arguments. In J.A. Blair, and R.H. Johnson (eds.), Conductive Argument: An Overlooked Type of Defeasible Reasoning (pp. 52-61). London: College Publications.

Johnson, R., and Blair, A. 2000. Informal logic: An overview. Informal Logic 20: 93-107.

Kenny, A.J. 1966. Practical inference. Analysis 26: 65-75.

Kock, C. 2007. Is practical reasoning presumptive? Informal Logic 27: 91108.

Kock, C. 2009. Choice is not true or false: the domain of rhetorical argumentation. Argumentation 23: 61-80.

Korb, K. 2004. Bayesian informal logic and fallacy. Informal Logic 24: 41-70.

Lakatos, I. 1978. The Methodology of Scientific Research Programmes (eds., J. Worrall, and G. Currie). New York: Cambridge University Press.

Oaksford, M., and Hahn, U. 2004. A Bayesian approach to the argument from ignorance. Canadian Journal for Experimental Psychology 58: $75-85$.

Perelman, C., and Olbrechts-Tyteca, L. 1969. The New Rhetoric. A Treatise on Argumentation. (J. Wilkinson, and P., Weaver, Trans.). Notre Dame: University of Notre Dame Press (Original work published 1958). 
Pearl, J., and Mackenzie, D. 2018. The Book of Why: The New Science of Cause and Effect. London: Basic Books.

Pollock J.L. 1987. Defeasible reasoning. Cognitive Science 11: 481-518.

Selinger, M., and Koszowy, M. 2016. Considering Carneades as a framework for informal logic: A reply to Walton and Gordon. Informal Logic 36: 217-237.

Snoek Henkemans, A.F. 2001. Argumentation structure. In F.H. van Eemeren (ed.), Crucial Concepts in Argumentation Theory (pp. 101-134). Amsterdam: Amsterdam University Press.

Spohn, W. 2012. The Laws of Belief: Ranking Theory and Its Philosophical Applications. New York: Oxford University Press.

Strevens, M. 2017. Notes on Bayesian Confirmation Theory. http://www.strevens.org/bct/.

Tindale, C.W. 1999. Acts of Arguing. A Rhetorical Model of Argument. Albany: State University of New York Press.

Tindale, C.W. 2004. Rhetorical Argumentation. Principles of Theory and Practice. Thousand Oaks: Sage.

Toulmin, S.E. 2003. The Uses of Argument (Updated ed.). Cambridge: Cambridge University Press (1 st ed., 1958).

van Eemeren, F.H., and Grootendorst, R. 1992. Argumentation, Communication, and Fallacies: A Pragma-dialectical Perspective. Hillsdale: Lawrence Erlbaum.

van Eemeren, F.H. 2001. Fallacies. In F.H. van Eemeren (ed.), Crucial Concepts in Argumentation Theory (pp. 135-164). Amsterdam: Amsterdam University Press.

van Eemeren, F. H., Grootendorst R., and Snoeck Henkemans, A. F. 2002. Argumentation. Analysis, Evaluation, Presentation. Mahwah: Routledge/Lawrence Erlbaum. 
van Eemeren, F. H., Garssen, B., Krabbe, E.C.W., Henkemans, F.S., Verheij, B., and Wagemans, J.H.M. 2014. Handbook of Argumentation Theory. Dordrecht: Springer Netherlands.

van Laar, J. 2014. Arguments that take counter-considerations into account. Informal Logic 34: 240-272.

Walton, D. 2001. Abductive, presumptive and plausible arguments. Informal Logic 21: 141-169.

Walton, D. 2011. Conductive arguments in ethical deliberation. In J.A. Blair, and R.H. Johnson (eds.), Conductive Argument: An Overlooked Type of Defeasible Reasoning (pp. 191-209). London: College Publications.

Walton, D., and Gordon, T.F. 2015. Formalizing informal logic. Informal Logic 35: 508-538.

Wellman, C. 1971. Challenge and Response. Justification in Ethics. Carbondale and Edwardsville: Southern Illinois University Press.

Wenzel, J. W. 1992. Perspectives on argument. In W. L. Benoìt, D. Hample, and P.J. Benoit (eds.), Readings in Argumentation (pp. 121-143). Berlin-New York: Foris.

Witte, E.H., and Zenker, F. 2017. From discovery to justification. Outline of an ideal research program in empirical psychology. Frontiers in Psychology. https://doi.org/10.3389/fpsyg.2017.01847

Wohlrapp, H. 1998. A new light on non deductive argumentation schemes. Argumentation 12: 341-350.

Wohlrapp, H. 2014. The Concept of Argument. Dordrecht: Springer.

Woods, J. 2013. Reasoning errors. London, U.K.: College Press.

Xie, Y. 2017. Conductive argument as a mode of strategic maneuvering. Informal Logic 37: 2-22. 
Zenker, F. 2010. Deduction, induction, conduction: An attempt at unifying natural language argument structure. In J.A. Blair, and R.H. Johnson (eds.), Conductive Argument: An Overlooked Type of Defeasible Reasoning (pp. 74-85). London: College Publications.

Zenker, F. 2011. Experts and Bias: When is the interest-based objection to expert argumentation sound? Argumentation 25: 355-370.

Zenker, F. 2013a. What do normative approaches to argumentation stand to gain from rhetorical insights? Philosophy \& Rhetoric 46(4): 415-436.

Zenker, F. (ed.). 2013b. Bayesian Argumentation: The Practical Side of Probability. (Synthese Library, Vol. 362). Dordrecht: Springer. 